\title{
Enhanced Corrosion Resistance of Silicone-Modified Epoxy Coatings by Surface-Wave Plasma Treatment
}

\author{
Tao Xu ${ }^{1 \#}$, Heqing Li ${ }^{2 \#}$, Jing Song ${ }^{3}$, Guilian Wang ${ }^{1}$, Seiji Samukawa ${ }^{4}$, Xijiang Chang ${ }^{{ }^{*}}$, Jingxia Yang $^{2 *}$ \\ ${ }^{1}$ College of Electronic and Electric Engineering, Shanghai University of Engineering Science, 333 \\ Long Teng Road, 201620, Shanghai, China \\ ${ }^{2}$ College of Chemistry and Chemical Engineering, Shanghai University of Engineering Science, 333 \\ Long Teng Road, 201620, Shanghai, China \\ ${ }^{3}$ Fashion \& Art Design Institute, Donghua University, 1882 West Yanan Road, 200051, Shanghai, \\ China \\ ${ }^{4}$ Advanced Institute for Materials Research, Institute of Fluid Science, Tohoku University, 2-1-1 \\ Katahira, Aoba-ku, Sendai, 980-8577, Japan \\ \# T. Xu and H. Li contributed equally in this work. \\ *E-mail: 091031001@fudan.edu.cn (X. Chang); yjx09tj@foxmail.com (J. Yang)
}

doi: $10.20964 / 2019.06 .18$

Received: 4 February 2019 / Accepted: 13 March 2019 / Published: 10 May 2019

Silicone-modified epoxy coatings were prepared and treated under different plasma atmospheres in order to enhance their anticorrosion ability. The corrosion current density, corrosion potential and impedance of the modified coatings were measured by an electrochemical workstation. The results showed that the corrosion resistances of silicone-modified epoxy coatings were highly improved by surface-wave plasma treatment. Compared with the original coating, the corrosion current density of these coatings modified by plasma decreased from $0.5976 \mu \mathrm{A} / \mathrm{cm}^{2}$ to the minimum of $0.0058 \mu \mathrm{A} / \mathrm{cm}^{2}$ and the impedance increased from $1.925 \times 10^{3} \Omega \cdot \mathrm{cm}^{2}$ to the maximum of $2.938 \times 10^{6} \Omega \cdot \mathrm{cm}^{2}$, in which Ar plasma showed the best significant effect.

Keywords: silicone-modified epoxy, surface wave plasma, surface modification, corrosion resistance

\section{$\underline{\text { FULL TEXT }}$}

(C) 2019 The Authors. Published by ESG (www.electrochemsci.org). This article is an open access article distributed under the terms and conditions of the Creative Commons Attribution license (http://creativecommons.org/licenses/by/4.0/). 